\title{
FUEL TANK CRASHWORTHINESS: LOADING SCENARIOS
}

\author{
Karina Jacobsen \\ Volpe National Transportation Systems Center \\ US Department of Transportation \\ Cambridge, MA 02142 \\ www.volpe.dot.gov
}

\begin{abstract}
The Federal Railroad Administration's Office of Research and Development is conducting research into fuel tank crashworthiness. The breaching of fuel tanks during passenger rail collisions and derailments increases the potential of serious injury and fatality due to fire. This paper identifies and describes common collision loading scenarios for locomotive fuel tanks on the U.S. general railroad system. Developing scenarios that characterize this situation is the first step in crashworthiness research methodology for improving rail equipment safety.
\end{abstract}

A survey of accidents within the U.S. between 1995 and present was used to identify fuel tank impact scenarios as follows: impact with adjacent railcar component; oblique impact with another railcar; rollover leading to impact with another railcar; derailment or rollover leading to grounding; and impact with rail. These collision scenarios are further categorized by the types of collision modes experienced by the fuel tank, i.e. impact type and impact location. These loading conditions establish targets for evaluating current levels of fuel tank integrity and potentially developing improved strategies for enhancing fuel tank integrity.

\section{INTRODUCTION}

As part of the Federal Railroad Administration's Equipment Safety Research Program, accident investigations have been conducted since 1996 to determine the causal mechanisms of injury and fatality in train collisions and derailments. The results of accident investigations have helped guide research efforts to improve passenger rail equipment crashworthiness in the U.S. Such efforts include, the development of improved passenger car end frame requirements [1, 2], development of crash energy management specifications for passenger trains and locomotives [3, 4] and improved interior occupant features such as seats and tables $[5,6]$.

Fuel tank research is being conducted to determine strategies for decreasing the likelihood of tank rupture and the resultant threat of a post-collision or derailment fire. Existing regulations require that fuel tanks support static loads without failure. Current research is focusing on understanding the impact response of the fuel tanks under dynamic loading. Utilizing the same approach that has been effective in increasing the structural crashworthiness of passenger railcars, improved strategies can be developed that will address the types of loading conditions experienced in a collision or derailment event. This information can be used to develop performance-based requirements, which address known safety hazards and can typically be applied to a wide range of fuel tank designs and equipment.

\section{Research Methodology}

The overall objective of the rail equipment crashworthiness research is to develop strategies for improving safety over existing designs. The process shown in Figure 1 guides the research efforts. Conducting accident investigations and surveying accident databases identify primary collision scenarios of concern. Such scenarios are idealized to then evaluate existing designs with testing and analyses tools. The evaluation strategy establishes the crashworthiness performance metrics and the test requirements needed to provide the appropriate measurements. Existing equipment is evaluated for the chosen collision scenario to establish a baseline level of crashworthiness. Alternative designs are evaluated in the same idealized collision scenario and using the chosen measures of crashworthiness (i.e. energy absorbed, total crush/deflection, modes of deformation, etc.) comparisons are made to the baseline level of crashworthiness. The 
development and validation of analysis techniques play a key role in evaluating alternative designs. Validated models are used to extrapolate to other collision conditions and evaluate the performance of other designs. The research results are used by the FRA to support rule-making that improves occupant protection in rail travel.

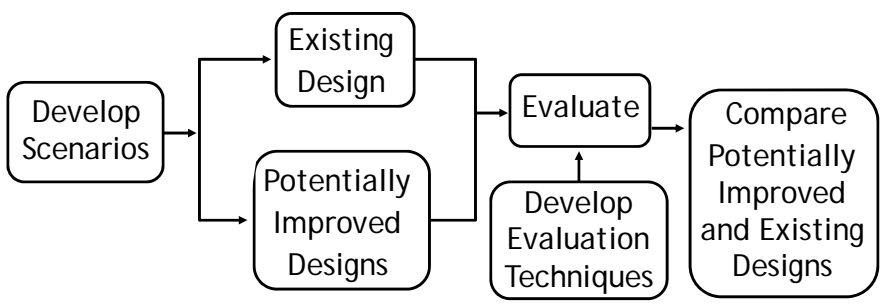

Figure 1. Flow diagram illustrating crashworthiness research methodology.

\section{Fuel Tank Crashworthiness}

The overall objective of the fuel tank research is to develop strategies for improving fuel tank integrity over existing designs. The research flow diagram shown above is used to evaluate and compare fuel tank crashworthiness of existing designs with improved design strategies. This paper sets up the supporting information for developing scenarios and highlights the performance of some existing fuel tank designs. The objectives of this paper are to use accident histories in the U.S to first, identify train collision or derailment scenarios that lead to fuel tank ruptures and second, categorize the types of loading conditions experienced by fuel tanks.

In the U.S., conventional freight locomotives account for the majority of fuel tanks used in rail transportation, but other types of equipment include passenger locomotives and diesel multiple units (DMUs). Conventional freight locomotives and conventional passenger locomotives tend to share similar fuel tank design strategies. On conventional locomotives the fuel tank is typically located beneath the main structure between the front and rear trucks. To optimize space, fuel tanks may span close to the full-width of the locomotive underframe and extend down to a few inches above rail. General design styles range from underslung tanks to integrated designs that are framed by the main longitudinal members (i.e. side sills and center beam). The accident/derailment survey identifies the range of impacts sustained by conventional locomotive fuel tank designs and the consequences. These incidents highlight the post-collision or derailment threat that may arise from spilled fuel. If an ignition source is present, such as a spark, fire can pose a threat to passengers trapped in or attempting to exit the wreckage.

The scope of this paper is to address fuel tank crashworthiness for passenger train applications. With the increased popularity of operating DMUs in the U.S., understanding the potential threats that occur in the general railroad system is an important first step for then assessing fuel tank integrity of this equipment. Trainsets made up of DMUs are unique in that passengers are in closer proximity to the fuel tank than with passenger trainsets pushed or pulled by conventional locomotives. While this accident/derailment survey presents examples exclusively of conventional locomotive fuel tank ruptures, loading scenarios can be applied to developing alternative strategies that improve fuel tank integrity for both conventional locomotives and DMUs.

\section{ACCIDENTS}

This section describes a selection of incidents on the U.S. general railroad system during which the fuel tanks were breached. The data was gleaned from the FRA RAIRS database and the FRA/Volpe Forensic Accident Investigations. Seven incidents have been grouped together based on the type of impact that led to the fuel tank rupture. Some of these example incidents highlight multiple types of fuel tank impacts occurring within the single incident. The incidents are categorized as follows:

1. Impact with surrounding railcar component

2. Oblique impact with another railcar

3. Rollover leading to impact with another railcar

4. Derailment or rollover leading to grounding

5. Impact with rail

This method highlights three important factors of the incident: 1) the impacting object (e.g. other rail vehicle, truck, adjacent component, rail, etc.), 2) the type of impact (e.g. blunt, raking, etc.) and 3) the location of impact on the fuel tank. Additionally, the categories allow the likelihood of each type of impact to be considered. This information can then be used to guide the prioritization of and the development of alternative strategies for improving fuel tank integrity.

\section{Impact with Surrounding Railcar Component}

During accidents in which the substructure of the locomotive is loaded, the components below the underframe may become detached or deformed allowing them to impact or load adjacent components. This type of scenario has been observed to compromise fuel tank integrity. The following accidents include head-on train-to-train impacts and oblique collisions, highlighting that this category of fuel tank impact scenario is independent of train collision scenario.

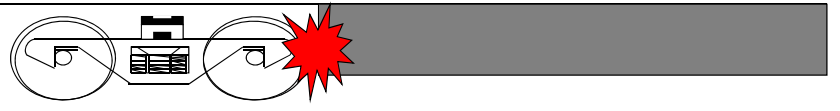

Figure 2. Schematic drawing, fuel tank impact with a surrounding railcar component

\section{Example 1: Syracuse, New York, February 5, 2001}

On February 5, 2001, an intercity passenger train rear-ended a freight train with a closing speed between $28 \mathrm{mph}$ to $35 \mathrm{mph}$ 
[7, 8]. Both trains were traveling eastbound at the time of impact. The lead passenger locomotive was exiting a 1.5 degree curve at between $35 \mathrm{mph}$ and $42 \mathrm{mph}$ when it impacted the trailing end of the freight train, which was traveling at about $7 \mathrm{mph}$. The passenger train was led by two EMD F40 locomotives, followed by a coach car (dinette) and four conventional coach cars. The freight train comprised of 88 loaded cars, four empty cars, and two locomotives at the lead. The trailing cars of the freight train were bulkhead flatcars. Neither train derailed. The freight cars remained in-line, on the tracks, and the track did not buckle. The two passenger locomotives remained in-line and on the tracks. The following four passenger cars experienced sawtooth lateral buckling.

The fuel tank of the lead passenger locomotive was breached during accident. The car-to-car interaction between the impacting equipment caused a sequence of events that deformed the substructure of the locomotive. The flatcar construction consists of a stiff underframe and a bulkhead sheet making up the end structure. As the locomotive impacted the bulkhead flatcar, the flatcar's underframe structure, including the draft sill and coupler remained essentially intact, while the bulkhead crushed by approximately 6 feet, conforming to the shape of the locomotive platform and hood. The flatcar's coupler and draft sill penetrated beneath the locomotive floor, first tearing off the locomotive coupler and draft gear box, then loading the lead traction motor and front of the body bolster. As a result, the front locomotive truck detached and impacted the adjacent fuel tank. Figure 3 shows the adjacent truck lug that punctured into the fuel tank.

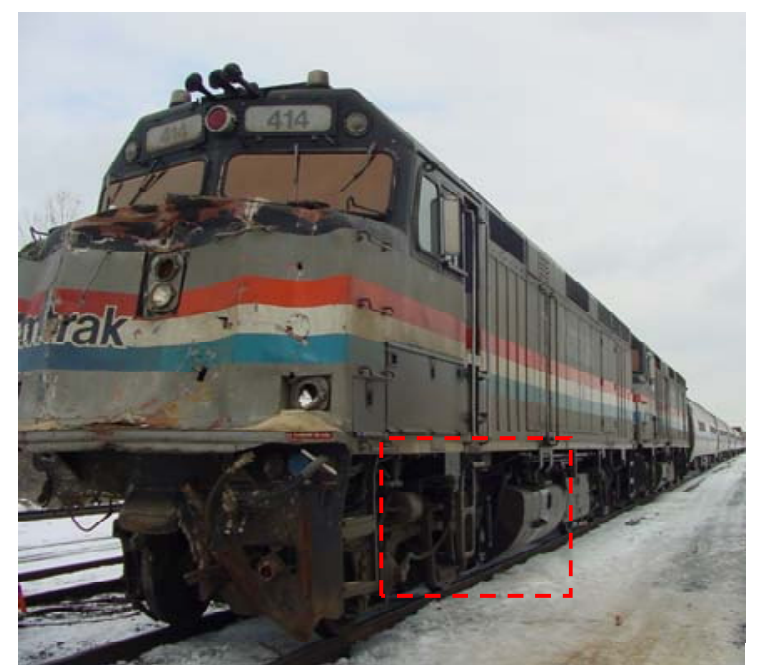

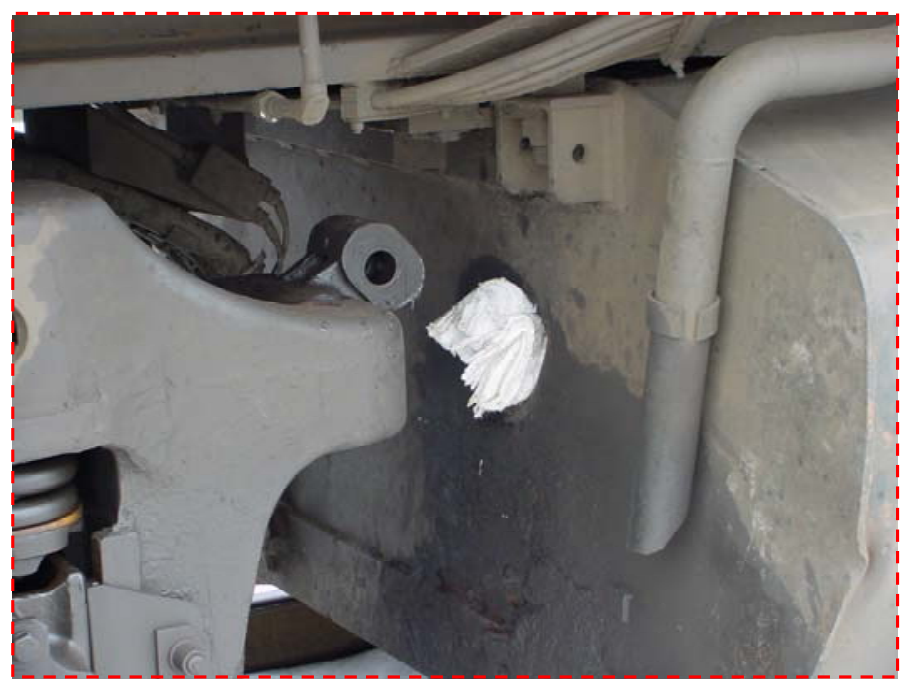

Figure 3. Post-accident photographs: Top, showing the EMD F40 passenger locomotive and bottom, showing a close-up view of the punctured front face of the fuel tank.

Example 2: Chicago, Illinois, November 30, 2007

On November 30, 2007, an Amtrak passenger train rear-ended a standing freight train at approximately $33 \mathrm{mph}[9,10]$. The passenger train was led by a GE P42 Genesis Series 1 Diesel Electric locomotive, followed by three coach cars. The freight train consisted of two locomotives and 20 multi-platform intermodal cars, the rear car being a flatcar carrying containers. The final configuration of the impacting equipment is shown in an aerial view in Figure 4. The passenger locomotive was the only derailed equipment; it overrode the last car of the freight train, coming to rest on the flatcar's container.

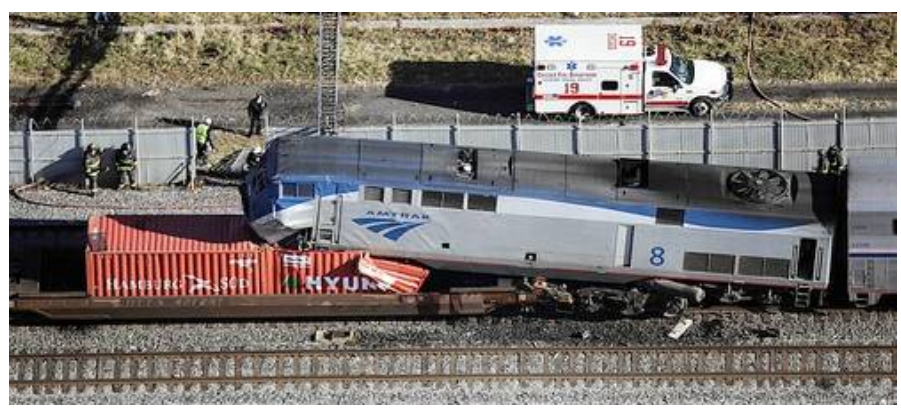

Figure 4. Post-accident photograph, passenger train locomotive overrode flatcar.

The fuel tank of the passenger locomotive was breached during the accident. Upon impact of the locomotive and loaded flatcar, the locomotive draft gear bottomed out and the freight car draft sill deformed downward, causing a catapult mechanism and instigating the overriding motion from the locomotive. The locomotive striker plate impacted the flatcar bolster and with the failure of the draft gear housing the locomotive nose deformed back and upward. The lead truck essentially became pinned between the freight car and the locomotive and with the continued overriding of the 
locomotive, the truck attachments failed. As the locomotive was dragged against the truck, the wheels impacted the slope sheet of the fuel tank. Figure 5 shows two views of the front face of the Amtrak Genesis fuel tank. On this design, the front face is known as the slope sheet. The photos show the initial scarring and progressive puncture from the impact with the truck wheel. The tear in the fuel tank was approximately two feet. About 300 gallons of diesel fuel spilled from the tank.

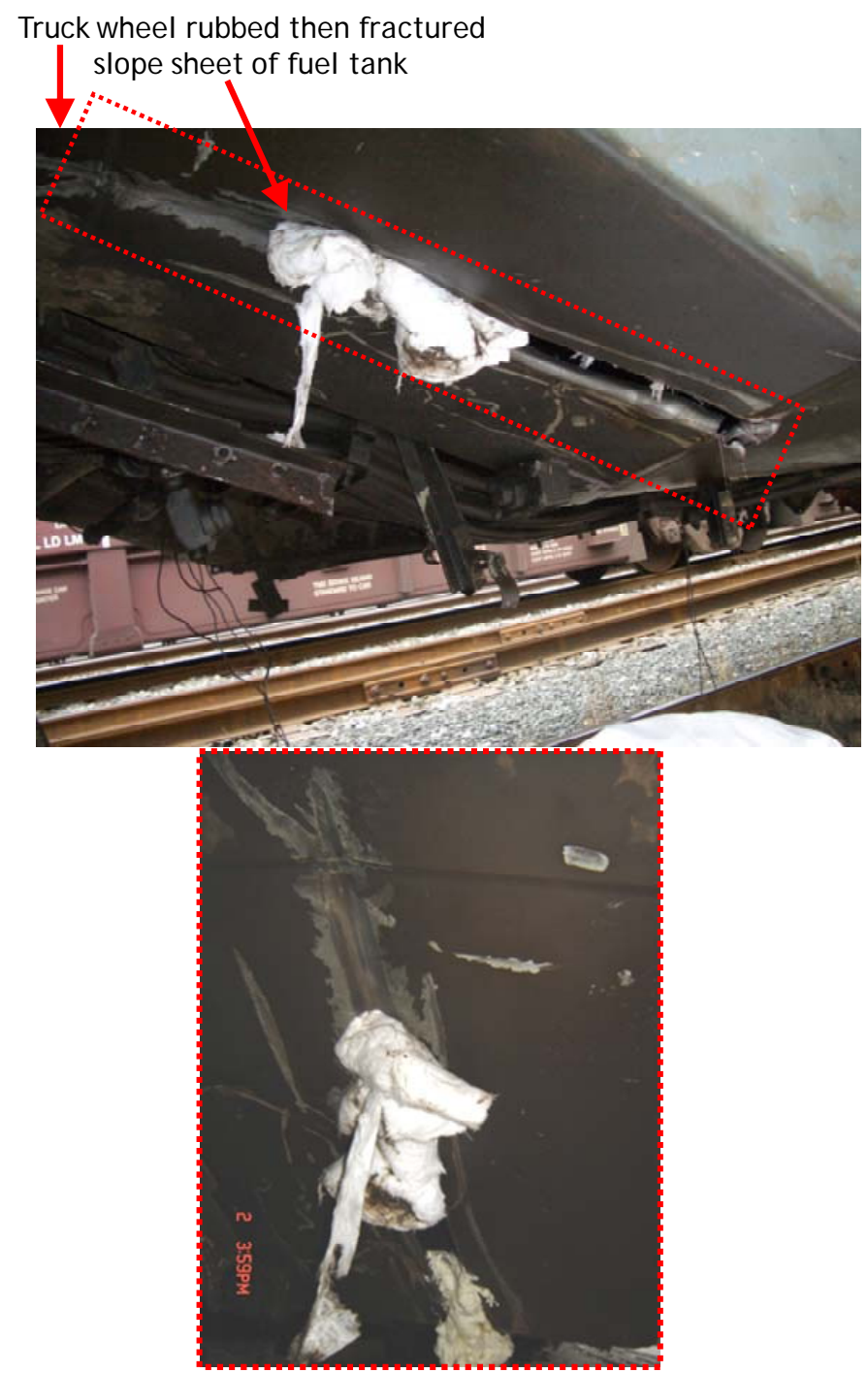

Figure 5. Post-accident photographs of the fuel tank: Top, sideview of the front face "slope sheet" of fuel tank and bottom, closeup of fractured slope sheet.

\section{Example 3: Fullerton, California, November 18, 1999}

On November 18, 1999, a Metrolink commuter train traveling at about $45 \mathrm{mph}$ and a BNSF freight train impacted at a switch $[11,12]$. The trains were traveling in opposite directions and impacted while the freight train was being switched to a sideline. The passenger train consisted of a F59PH locomotive and four passenger cars. The freight train was 65 cars in length. The passenger train struck the flatcars at the middle of the freight consist as they traversed the switch. The passenger locomotive derailed but all the following passenger cars remained on the tracks. The freight train had four overturned cars and six derailed. Figure 6 shows the final position of the derailed locomotive and two adjacent freight cars.

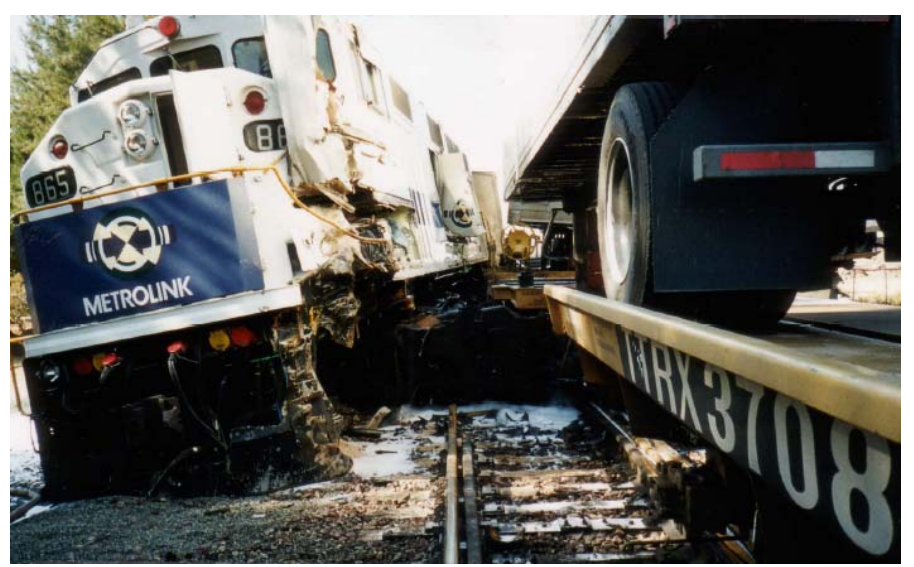

Figure 6. Post-accident photograph of colliding equipment.

As the passenger locomotive obliquely impacted the back of the freight train, the locomotive raked along the side of the trailing flatcars. The locomotive derailed, the lead locomotive truck became detached and rotated back, impacted and piercing the adjacent fuel tank, as shown in the photograph of Figure 7. An unknown quantity of fuel spilled from the breached fuel tank. A fire started but was extinguished by firefighters.

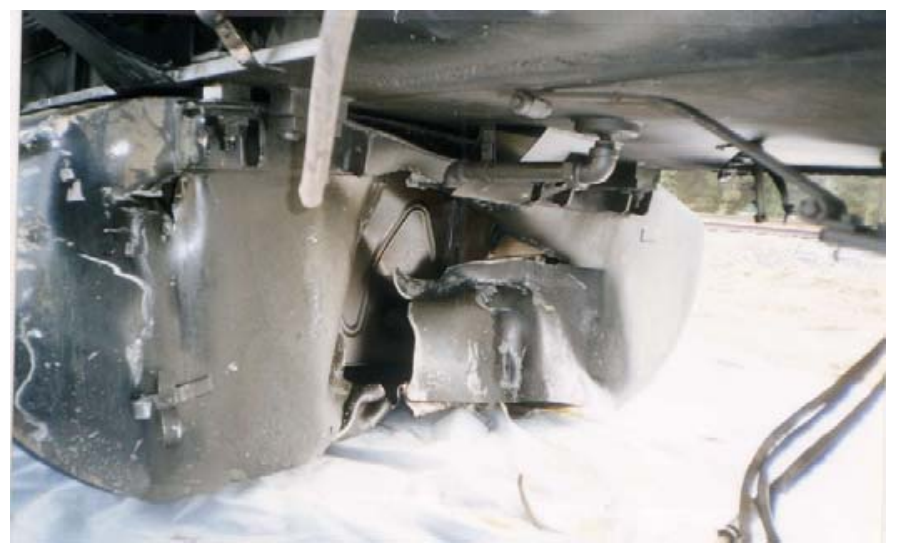

Figure 7. Post-accident photograph of front face of lead passenger locomotive fuel tank.

\section{Oblique Impact with Another Railcar}

Fuel tanks are typically attached to the underframe of a locomotive or DMU and span nearly the full width of the car to optimize space. This presents a situation in which the side of the tank is exposed in oblique collisions. An oblique collision between two trains or rail vehicles can challenge fuel tanks with a blunt impact and/or raking impact. Figure 8 shows a schematic illustration of rail equipment on intersecting tracks. 
The schematic illustrates how the orientation of the equipment may create a raking collision between equipment. The following example collisions in Fullerton, California and Silver Spring, Maryland, highlight this scenario and consequences of fuel tank rupture.

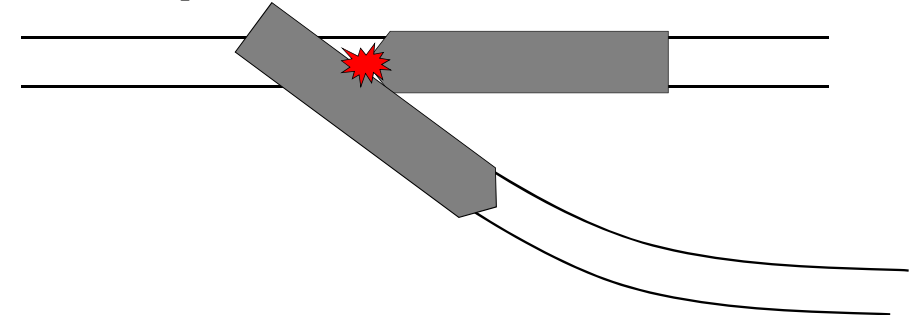

Figure 8. Schematic drawing, oblique impact between two rail vehicles.

Example 1: Fullerton, California, November 18, 1999

The oblique train-to-train collision in Fullerton, California on November 18, 1999 is described in the last section. In this collision, a passenger train impacted a freight train being moved onto a siding, which oriented the cars for an oblique impact between the rear corner of the flatcar and the left side of the locomotive. Figure 6 shows the final positions of the equipment. Deformation can be seen on the side of the locomotive, from the freight car gouging into the side. The largest gouge mark is located just under the left side of the cab compartment.

As the two pieces of equipment continued to rake against each other, the side structure of the flatcar pierced into the left side of the fuel tank, as shown in Figure 9. The fuel tank tore open along the top edge of the left side and along the front seam between the front panel and the left side panel. The internal baffles are visible, oriented laterally across the full width of the tank.

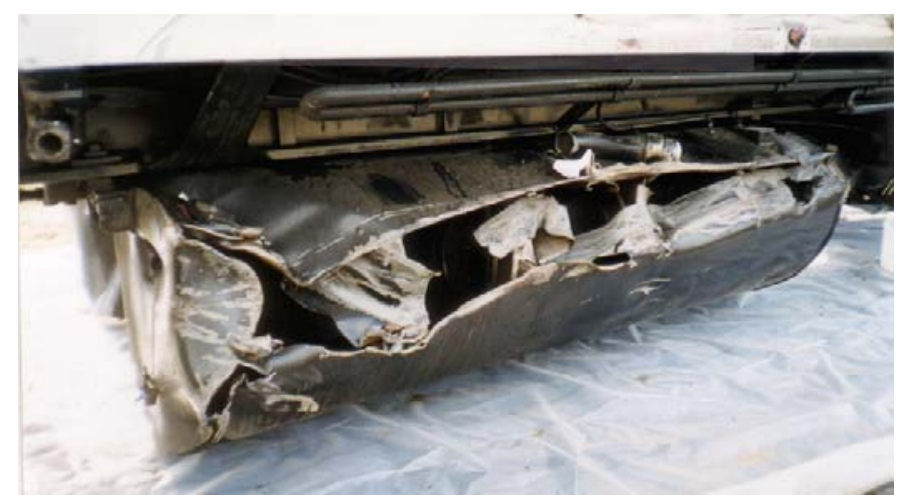

Figure 9 Post-accident photograph of left side of passenger locomotive fuel tank showing tear marks.

Example 2: Silver Spring, Maryland, February 16, 1996

On February 16, 1996, a locomotive-led intercity passenger train was entering a switch at approximately $30 \mathrm{mph}$ when it was struck nearly head-on by a cab-car led commuter train, traveling at about $40 \mathrm{mph}[7,13]$. The intercity train was led by a F40PH locomotive and a P40, six material handling cars, a baggage car, three sleeper cars, a dining car, a lounge car, two coach cars and a dormitory car. The commuter train consisted of a cab car, two coach cars and a GP39-H2 locomotive. Because the locomotive-led train had just entered a switch at the time of impact, the locomotive and cab car were offset - the cab car coupler was approximately aligned with the left side of the locomotive. Both experienced severe damage at this impact interface. The cab car then raked along the side of the locomotive causing severe structural damage intruding into the passenger compartment and shearing off equipment from the locomotive. Both locomotives of the intercity train derailed and all cars in the commuter train derailed. The photograph in Figure 10 shows the post-collision wreckage.

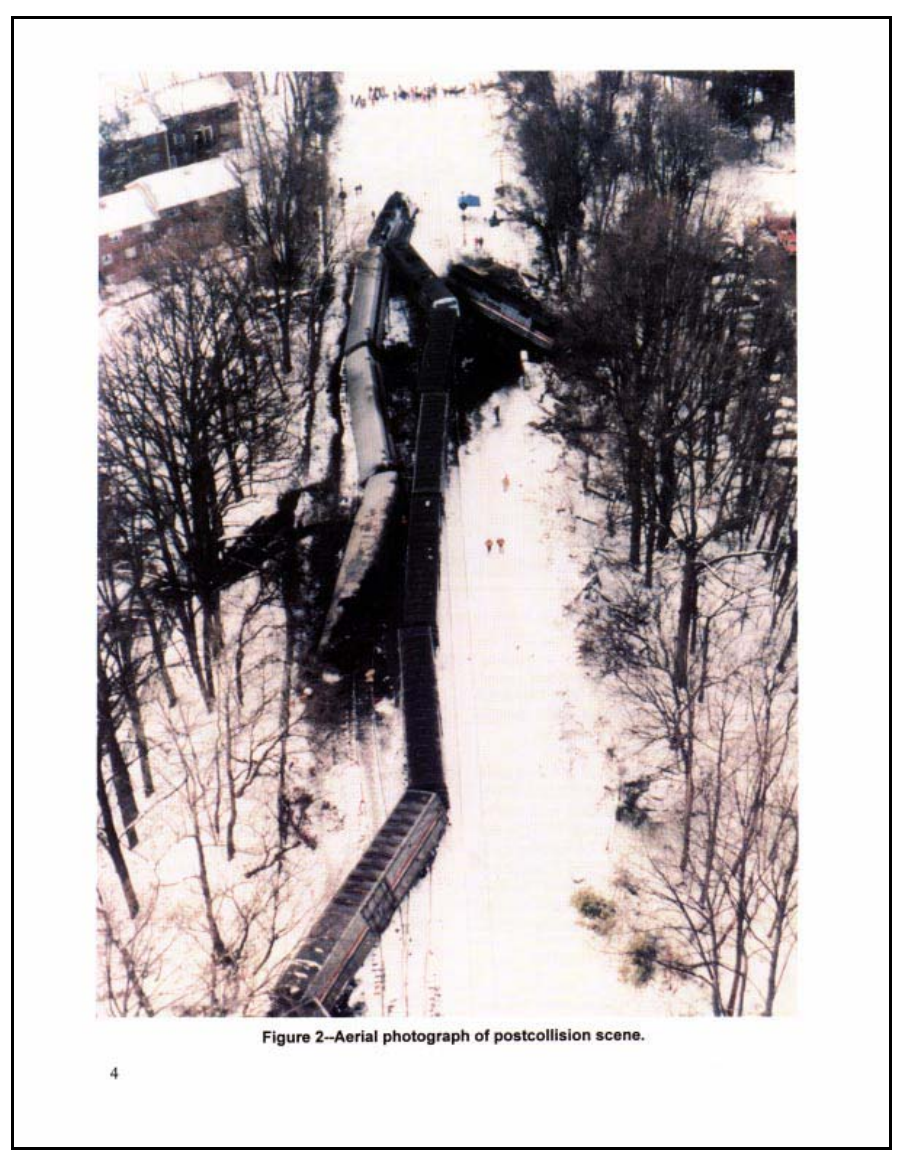

Figure 10. Photograph showing an aerial view of the Silver Spring, MD accident. (Image from NTSB report [13].)

The severity of the impact and the progressive raking collision caused the lead locomotive fuel tank to be punctured. The initial collision caused the locomotive to deform and the front truck to push back into adjacent fuel tank. As the equipment deflected past each other and the raking interaction took place, the cab car main structure, which is lower than the locomotive main platform, essentially stripped the under-hanging equipment off of the locomotive, gouging into the side of the 
fuel tank. The locomotive platform structure simultaneously pierced into the side structure and occupant compartment of the cab car, tearing into about a third of the car length. These two events caused the exposed interior of the cab car to be sprayed by fuel. Fire broke out and fire fighters reported the fire had enveloped the commuter cab car when they arrived on-scene; the fire was put out in 10 minutes [13] but it consumed the interior of the cab car. There were 11 fatalities, all on the cab car. The coroner attributed three of the eleven fatalities to the post-collision fire.

\section{Rollover Leading to Impact with Another Railcar}

Under severe collision conditions, train dynamics behavior may include large amplitude zigzag-pattern buckling of the trainset and rollover of individual cars. As a lateral buckle progresses through a trainset, individual cars may become decoupled, potentially overturning and beginning to pile up, and impacting into the sides of each other. If rollover of individual cars occurs, the underside of the car, and as such, the bottom of fuel tanks, is exposed to impacts from adjacent cars. Figure 11 shows a schematic illustration of an overturned car being struck by another rail vehicle. In these types of impacts, the fuel tank is subject to an impact by a coupler or similarly blunt component of the impacting piece of equipment. Numerous accidents can be identified and three are described in this paper, in which one or multiple trainsets have demonstrated this collision mode and fuel tanks have been challenged and compromised. In these cases, which fuel spills, and cars piled up in close proximity, the risk of fire may pose a higher threat to passengers and crew. The passengers are at greater risk, particularly when cars are overturned and emergency egress a more complex and lengthy process.

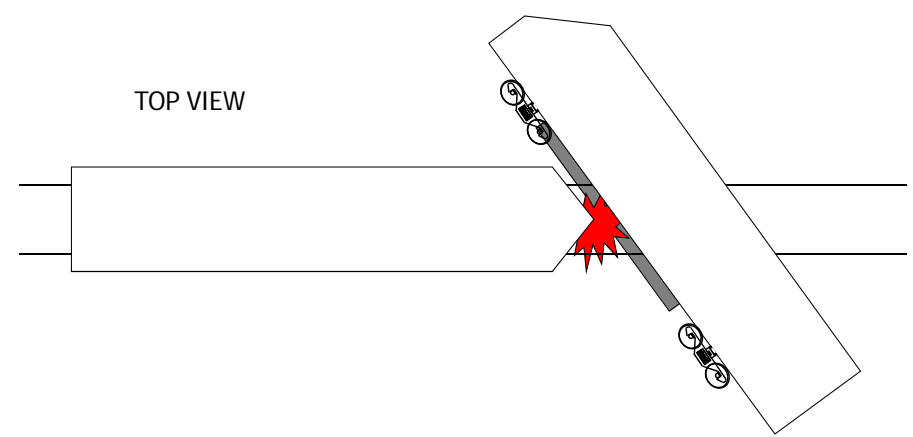

Figure 11. Schematic drawing, car-to-car impact, with one car overturned

Example 1: Bourbonnais, Illinois, March 15, 1999

On March 15, 1999 an intercity passenger train traveling at approximately $79 \mathrm{mph}$ struck a highway tractor-trailer truck carrying steel rebar at a grade crossing $[7,14]$. The passenger train derailed and proceeded to impact freight equipment located on an adjacent siding. The ten freight cars included a gondola car loaded with scrap steel and a covered hopper car loaded with fly ash, a fine residue of coal-burning, considered a hazardous waste. The passenger train was led by two GE P-40 Genesis locomotives, followed by a baggage car and 13 coach cars, including five sleeper cars, a dinette, and a lounge car. Both locomotives and 11 of the 14 passenger cars derailed. The photograph in Figure 12 shows the post-collision wreckage. The lead passenger locomotives are located with red ovals. The pile-up caused the second passenger car to bend around the end of the second locomotive. The third and fourth passenger cars rest up against the opposite side of the second passenger car, placing all the cars in close proximity.

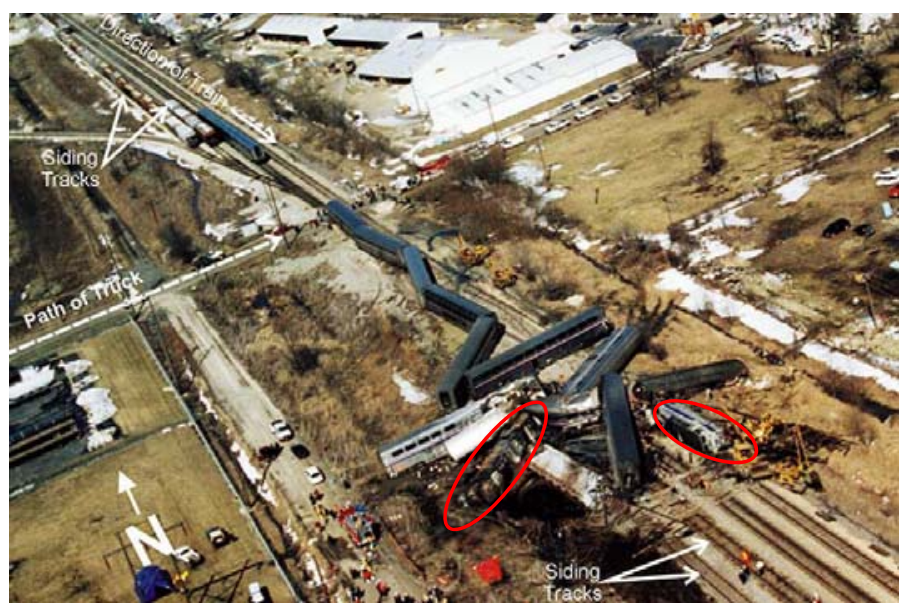

Figure 12. Post-accident aerial photograph of Bourbonnais, IL accident showing pile-up of passenger railcars.

During the progression of the collision and resulting pile-up, both locomotives experienced significant structural damage, including ruptured fuel tanks. The lead locomotive was significantly damaged on the left side. The fuel tank had multiple punctures. The Genesis locomotive fuel tanks are integrated in the locomotive underframe, spanning the full width of the locomotive and framed by the side sills. The second locomotive was damaged such that the back third of the underframe was bent into a ' $W$ ' shape and the equipment stripped off. The fuel tank was punctured in multiple locations. An unknown amount of fuel spilled from the locomotive fuel $\operatorname{tank(s)}$ and a fire ensued. Nearby civilians applied water until fire fighters arrived. There were 11 fatalities, all in the second passenger car, near the portion of car that was bent around the second locomotive. The coroner attributed at least five of the eleven injuries of these fatalities to the fire [14].

Example 2: Hutto, Texas, May 5, 1998

On May 5, 1998 an intercity passenger train traveling at approximately $51 \mathrm{mph}$ struck a garbage truck at a grade crossing $[15,16]$. The passenger train was led by two GE P-42 DC locomotives, followed by 7 coach cars, all of which derailed during the incident. The top photograph in Figure 13 shows the post-collision wreckage. The two passenger locomotives are on their sides and located in the photograph by boxes. The lead locomotive is indicated by a green dashed- 
dotted box on the right of the photo. The coupled ends of the first and second passenger cars are resting against the locomotive underframe. The second locomotive is indicated by a red dashed box on the left side of the photo. The front of the first passenger car is leaning against the underframe of the locomotive.

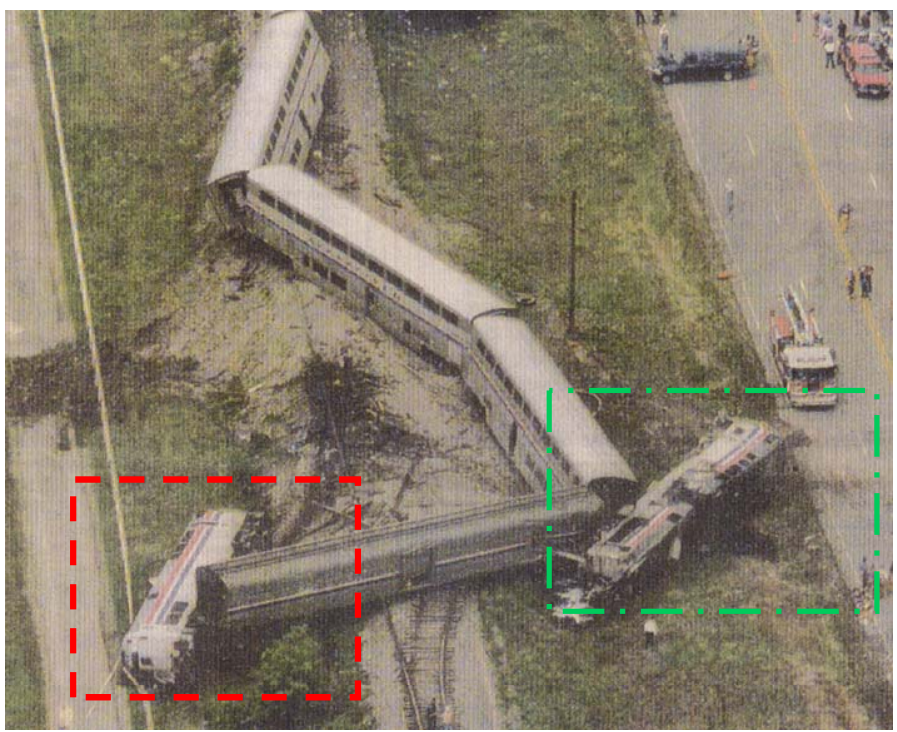

Figure 13. Post-accident photograph of Hutto, TX accident showing an aerial view of the wreckage. The green dashed-dotted box indicates the lead locomotive and the red dashed box indicates the second locomotive.

Rollover of the lead locomotive, followed by an impact of the trailing passenger cars caused the fuel tank to be ruptured by a blunt impact to the bottom. Figure 14 shows two photographs of the punctures in the lead locomotive fuel tank. This fuel tank is integrated into the underframe. Figure 15 shows a photograph of the orientation of the second locomotive and an adjacent passenger car. In this overturned position, the impact by the passenger car impacted the bottom of the fuel tank. A small fire broke out, but was extinguished by firefighters.
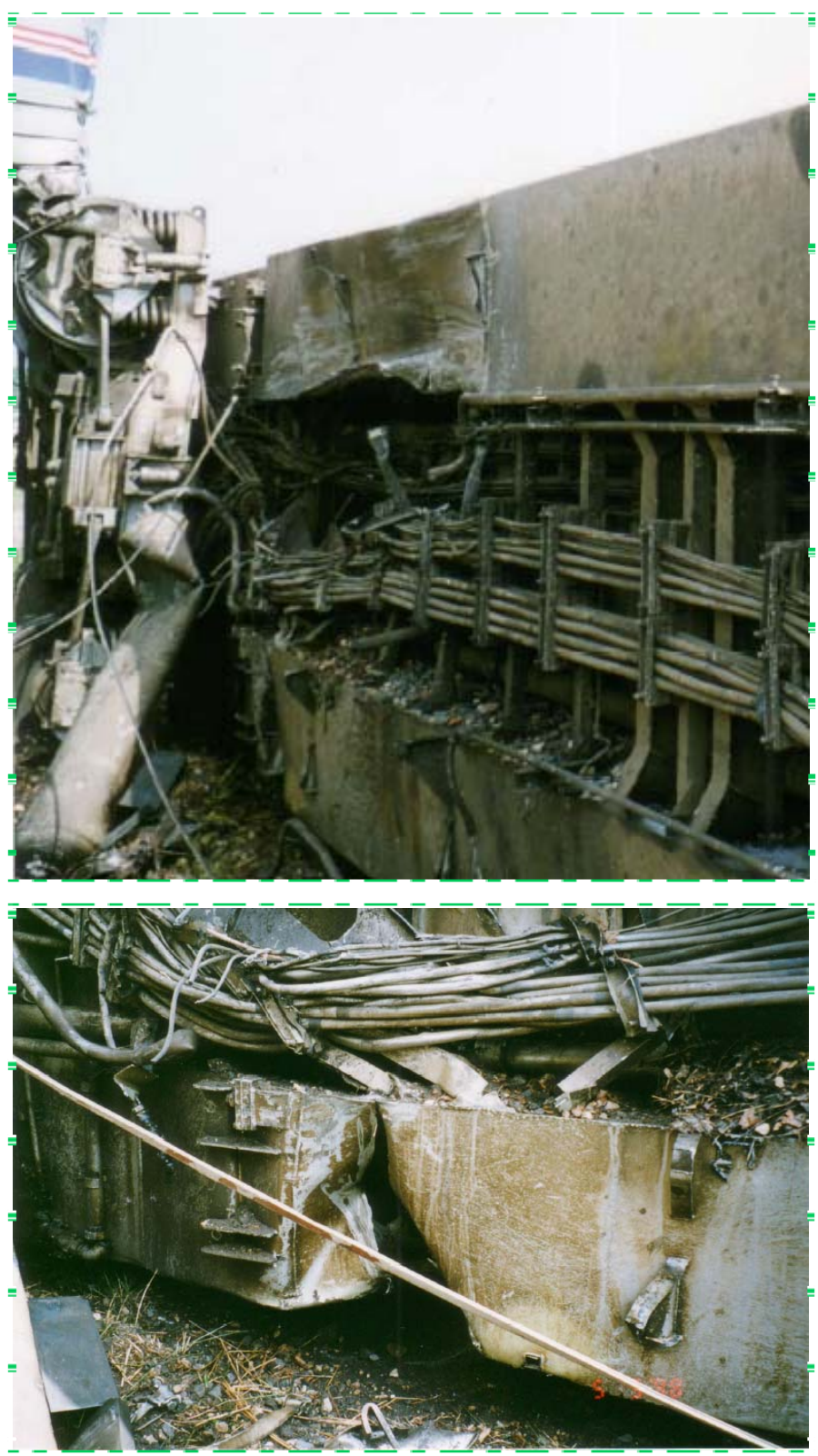

Figure 14. Photographs of the underframe of the lead locomotive unit showing punctures to both sides of fuel tank. 


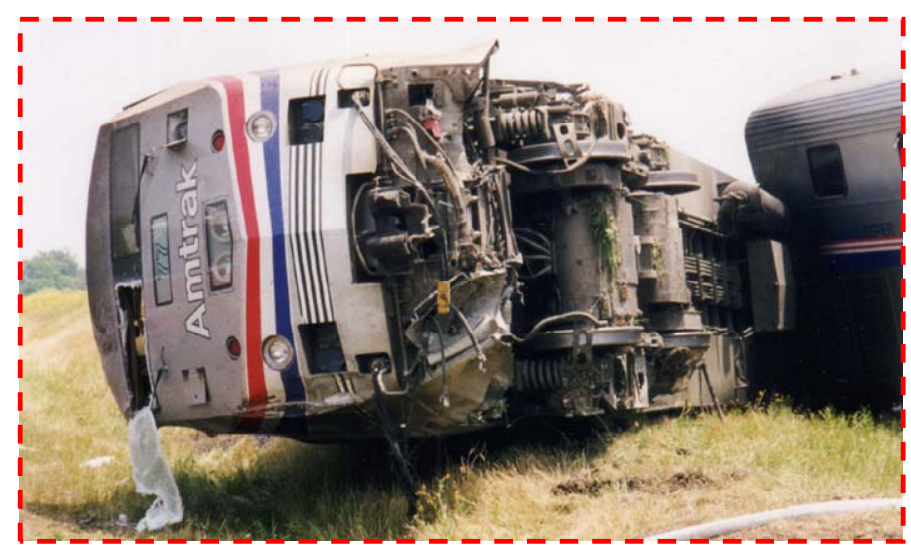

Figure 15. Post-accident photograph showing the overturned second locomotive and the passenger car leaning against the locomotive underframe.

\section{Derailment or Rollover Leading to Grounding}

In the event of a derailment or rollover event, a piece of equipment leaves the tracks and drags along the ground until it comes to rest. In this event the fuel tank may sustain a prolonged force, or dragging load scenario. Figure 16 shows a schematic illustration of a conventional fuel tank located on below the main structure of the locomotive being dragged along the ground. The following example collision in Bradford, Illinois shows a conventional freight locomotive that may have sustained a rupture from this type of loading scenario.

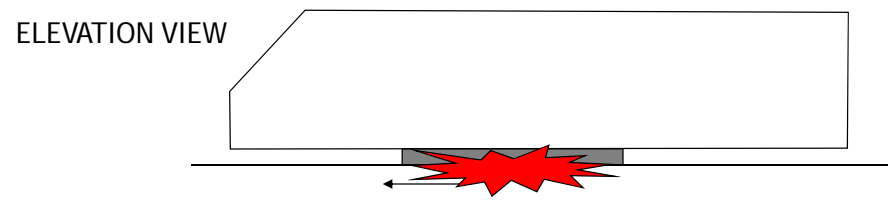

Figure 16. Schematic drawing illustrating a derailed piece of equipment, resulting in the fuel dragging along the ground.

\section{Example 1: Bradford, Illinois, January 2, 2002}

An accident in Bradford, Illinois is an example of a collision that challenged the fuel tank with multiple impact conditions. On January 2, 2002 two freight trains collided while one was midway into a siding, with a closing speed of approximately 44 mph [11]. This is another example of a side/raking incident from a train-to-train collision. The photograph shown in Figure 17 shows the EMD-SD40-2 locomotive derailed and resting on the ground. This collision example illustrates a combination of loading to the fuel tank. The fuel tank was likely dragged along the ground before the train came to its final position shown in the photograph. During this event the truck struck the fuel tank, causing the front face of the fuel tank to rupture.

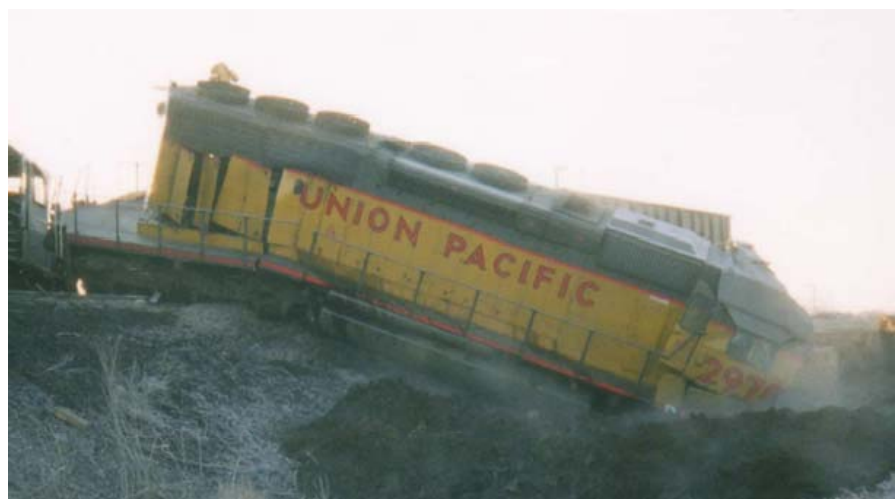

Figure 17. Bradford, IL post-accident photograph of locomotive.

\section{Impact with Rail or Other Object}

In the event of a derailment or collision event in which the equipment leaves the tracks, it is possible for the equipment to come to rest with the underside of the equipment resting on one or both rails. Figure 18 shows a schematic illustration of a piece of equipment resting perpendicular to the original direction of travel, straddling the tracks. Because the rails and tie structure is typically raised off of the ground, the piece of equipment would be suspended off of the ground and resting entirely on the rail or rails. The following example collision in Bradford, Illinois shows a conventional freight locomotive that may have sustained a rupture from this type of loading scenario.

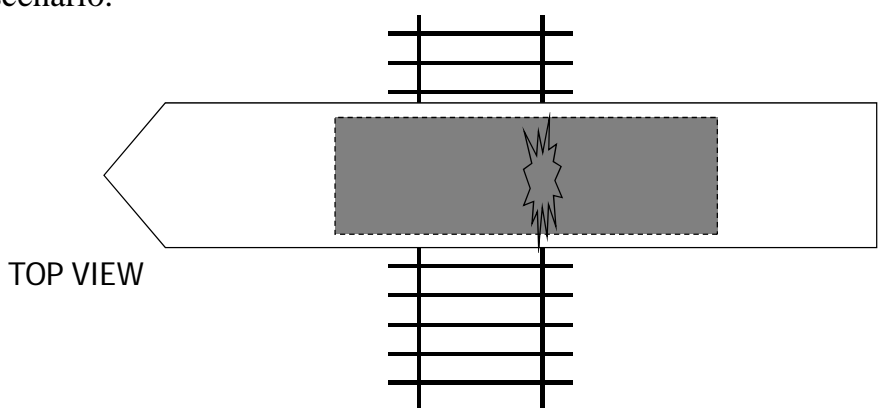

Figure 18. Schematic drawing showing a piece of equipment straddling the rails with the weight of the vehicle supported by the fuel tank.

\section{Example 1: Bradford, Illinois, January 2, 2002}

As described in the last section, the incident in Bradford, Illinois may fall into multiple categories for possible fuel tank loading types. The photograph shown in Figure 17 shows the EMD-SD40T-2 locomotive jack-knifed and oriented laterally across the rails. The fuel tank, circled in this photograph, spilled approximately 3,000 gallons of the 4,000-gallon capacity. The fuel tank sustained tears in the side sheet and bottom sheet which were likely caused by a combination of impacts with the rail and adjacent trucks or structural components during the collision event. 


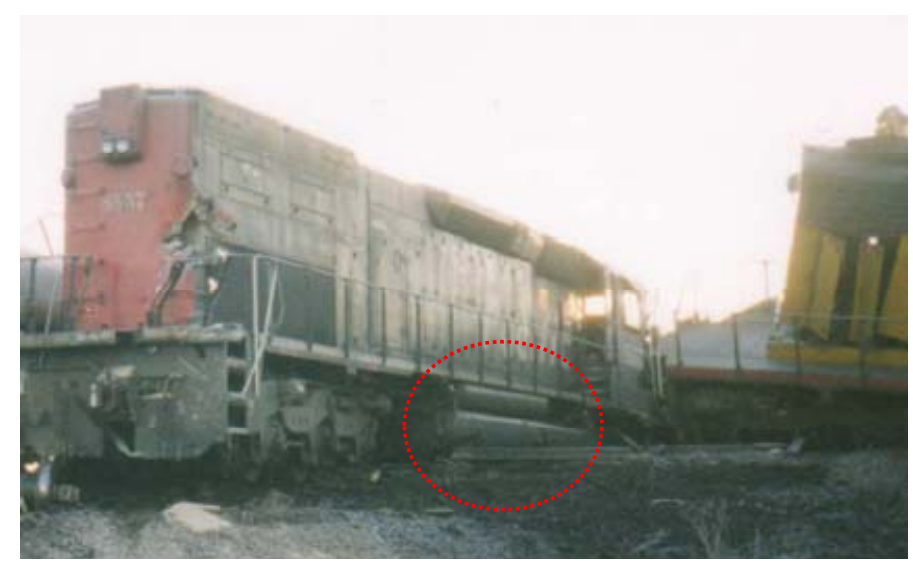

Figure 19. Bradford, IL post-accident photograph of locomotive straddling the rail.

\section{SUMMARY}

From the survey discussed in this paper, the accidents identified to have the most serious consequences, in terms of loss of life, are the Bourbonnais and Silver Spring incidents. In both incidents the train collision dynamics led to fuel tanks being impacted by another piece of equipment. The fuel tanks sustained multiple types of impacts, including side-swiping impacts to the side of the fuel tank, blunt impacts to the bottom of the fuel tank, and impacts to the front of the fuel tank from crushing of the locomotive and the detachment of surrounding equipment. The incidents indicate that with overturned equipment, the bottom impact is the most vulnerable surface of the tank and exposed to severe impacts from adjacent rail vehicles.

The accidents reviewed in this paper provide a framework for discussing the types of threats that may challenge fuel tank integrity. Table 1 was developed to summarize the results of the accident survey. The table shows a categorization of the types of incidents experienced by conventional locomotives and the resulting collision mode sustained by fuel tanks. A number of observations can be made from the accidents reviewed in this paper and the results shown in the table.

Table 1. Locomotive collision scenarios and related fuel tank collision modes.

\begin{tabular}{|l|l|l|}
\hline & Collision Scenario & Collision Mode \\
\hline 1 & $\begin{array}{l}\text { Impact with Surrounding Railcar } \\
\text { Component }\end{array}$ & Blunt Impact to End of Tank \\
\hline 2 & Oblique Impact with Another Railcar & $\begin{array}{l}\text { Raking of Side of Tank OR } \\
\text { Blunt Impact to Side of Tank }\end{array}$ \\
\hline 3 & $\begin{array}{l}\text { Rollover and Impact with Another } \\
\text { Railcar }\end{array}$ & Blunt Impact to Bottom of Tank \\
\hline 4 & Grounding & $\begin{array}{l}\text { Raking of Bottom or Side of Tank OR } \\
\text { Blunt Impact to Side of Tank }\end{array}$ \\
\hline 5 & Impact with Rail or Other Object & Blunt Impact to Bottom of Tank \\
\hline
\end{tabular}

The table highlights that all sides of the fuel tank may become exposed to impacts during the possible range of collision or derailment events. The ends of fuel tanks are most typically struck by adjacent trucks and surrounding structural components or mounted equipment. The bottoms of fuel tanks are exposed when the locomotive comes off the tracks and is then struck by other rail vehicles. The incidents reviewed also indicate that fuel tanks may be challenged by a combination of collision modes in a single incident. The types of loading sustained by the fuel tank may include blunt impacts or raking impacts.

\section{DISCUSSION}

The results in this paper highlight some safety measures that will minimize the likelihood of fuel tank breaches. First, a combination of collision avoidance and collision mitigation strategies help avoid collisions and keep the train on the tracks. Systems control features mitigate the likelihood of train derailments and collisions. Sophisticated PTC systems became required by federal regulation in 2010 to enhance collision prevention on the general railroad system. Crash energy management designs in passenger trains (both on locomotives and passenger cars) help manage the collision dynamics of a train during collisions. FRA has conducted research and developed standards to implement such improvements to passenger equipment, including improved crashworthiness features for passenger locomotives [4].

Second, ensuring attachment strength of the equipment mounted to the locomotive underframe will help minimize the likelihood of fuel tanks being struck by detached trucks and other components. For example, freight locomotive standards in the 1990s were revised to require the use of traction pins in truck-to-underframe design, which have minimized the likelihood of truck detachment in collisions. The locomotives cited in the Bradford, Illinois accident were built to older fuel tank and truck standards and may have performed more favorably with improved truck attachment strength requirements.

Third, alternative design strategies for fuel tank protection can limit the exposure of the fuel tanks to impacts and minimize the severity of impacts. Alternative strategies such as shielding to protect against impacts from surrounding components, crushable layers such as sandwich panels to absorb energy and blunt the load, and baffles that slow the ejection of fuel are some examples that may have potential to reduce the likelihood of fuel tank ruptures. Using idealized collision conditions, alternative strategies can be evaluated and the improvement demonstrated over existing designs.

\section{NEXT STEPS}

The most significant idealized fuel tank collision modes categorized in this paper are currently being evaluated for fuel 
tank designs. Alternative strategies have begun to be developed, including shielding to protect against impacts from surrounding components, crushable layers such as sandwich panels to absorb energy and blunt the load, and baffles to slow the ejection of fuel and compartments to reduce the ejection of fuel. The results of this research can be used to develop performance-based requirements, which address the identified safety hazards and can typically be applied to a wide range of fuel tank designs and equipment.

\section{ACKNOWLEDGEMENTS}

This work was performed as part of the Equipment Safety Research Program sponsored by the Federal Railroad Administration's Office of Research and Development. The authors would like to thank Eloy Martinez, (former) Program Manager, and Kevin Kesler, Division Chief, Equipment and Operating Practices Research Division, Office of Research and Development, Federal Railroad Administration, for all their support.

\section{REFERENCES}

1 Muhlanger, M., Llana, P., Tyrell, D. "Dynamic and QuasiStatic Grade Crossing Collision Tests" American Society of Mechanical Engineers, Paper No. JRC2009-63035, March 2009.

2 Code of Federal Regulations, Title 49, Part 238, Subpart CSpecific Requirements for Tier I Passenger Equipment.

3 Tyrell, D., Martinez, E., Jacobsen, K., Parent, D., Severson, K., Priante, M., Perlman, A.B., "Overview of a Crash Energy Management Specification for Passenger Rail Equipment," American Society of Mechanical Engineers, Paper No. JRC2006-94044, April 2006.

4 Llana, P., Stringfellow, R. "Preliminary Development of Locomotive Crashworthy Components" American Society of Mechanical Engineers, Paper No. JRC2011-56104, March 2011.

5 Severson, K., Perlman, B.A., Stringfellow, R. "Quasi-Static and Dynamic Sled Testing of Prototype Commuter Rail Passenger Seats" American Society of Mechanical Engineers, Paper No. JRC2008-63051, April 2008.

6 Parent, D., Tyrell, D., Rancatore, R., Perlman, A.B., "Design of a Workstation Table with Improved Crashworthiness Performance," American Society of Mechanical Engineers, Paper No. IMECE2005-82779, November 2005.

7 Tyrell, D., "Rail Passenger Equipment Accidents and the Evaluation of Crashworthiness Strategies," Journal of Rail and Rapid Transit, Proceedings Part F, Institute of Mechanical Engineers, August 2002.

8 National Transportation Safety Board, "Rear-end Collision of National Railroad Passenger Corporation (Amtrak) Train P286 with CSX Freight Train Q620 on the CSX Railroad at Syracuse, New York, February 5, 2001”, Adopted on November 27, 2001, NTSB/RAR-01/04.
9 Llana, P., Tyrell, D. "Reconstruction of the November 30, 2007, Chicago, IL Rail Collision" American Society of Mechanical Engineers, Paper No. JRC2011-56103, March 2011.

10 National Transportation Safety Board, "Collision of Amtrak Passenger Train 371 and Norfolk Southern Railway Company Freight Train 23M, Chicago, Illinois, November 30, 2007”, Adopted on March 31, 2009, NTSB/RAR-09/01.

11 Federal Railroad Administration, “Accident C-43-99 Crashworthiness Report on Locomotives and Cars, Southern California Regional Rail Authority (SC AX), Train SCAX 602Fullerton, California.” FRA Incident Report, 12/9/99, FRA RAIRS Database.

12 “Commuter Train and Freight Train Collide in California,” http://danger-

ahead.railfan.net/reports/rep99/fullerton19991118.html

13 National Transportation Safety Board, "Collision and Derailment of Maryland Rail Commuter MARC Train 286 and National Railroad Passenger Corporation AMTRAK Train 29 Near Silver Spring, MD February 16, 1996”, Adopted on July 3, 1997, NTSB/RAR-97-02.

14 National Transportation Safety Board, "Collision of National Railroad Passenger Corporation (Amtrak) Train 59 With a Loaded Truck-Semitrailer Combination at a Highway/Rail Grade Crossing in Bourbonnais, Illinois, March 15, 1999”, Adopted on February 5, 2002, NTSB/RAR-02-01.

15 Federal Railroad Administration, “Accident Report of Derailment on Amtrak Train \#22 at Hutto, Texas Reference No. C-19-98” FRA Incident Report, 10/13/98, FRA RAIRS Database.

16 Fikac, Peggy. "One Killed When Train, Garbage Truck Collide,” 1998, Abilene Reporter-News / Texnews / E.W. Scripps Publications.

http://www.texnews.com/1998/texas/derail0506.html 